\title{
HELPING STUDENTS OVERCOME BARRIERS TO BUSINESS COMMUNICATION NOWADAYS
}

https://doi.org/10.47743/jopafl-2021-21-01

\author{
Oana Alexandra ALEXA \\ Alexandru Ioan Cuza University of Iași, Faculty of Economics and Business \\ Administration \\ Iași, Romania \\ oana.alexa@uaic.ro
}

\begin{abstract}
Foreign language competence and cultural differences are often seen as the most common barriers to effective business communication and mastering them is understandably a long-term process, involving both targeted study and accumulating relevant practical experience. This paper will start by identifying other obstacles to effective communication that business people might encounter nowadays and then suggest some ways in which students preparing for a career in business would benefit from communication-focused activities in the classroom. It will show that an interdisciplinary approach is especially relevant at the moment, since the traditional channels and perspectives on business communication have been challenged in the context of the current global health crisis.
\end{abstract}

Keywords: Business communication, barriers, language, soft skills, hard skills.

This Article was presented as a paper at the $13^{\text {th }}$ edition of the Annual International Conference Globalization and Higher Education in Economics and Business Administration (GEBA 2021), which was held at the Alexandru Ioan Cuza University, Faculty of Economics and Business Administration in Iasi, Romania from the $21^{\text {st }}$ to $23^{\text {rd }}$ of October 2021.

\section{Introduction}

Business communication is a broad concept in itself, but in attempting to define it, we must first refer to communication in general. In its most basic form, communication involves transmitting a message from a sender to a receiver, through a specific channel. The word 'communication' itself is derived from the Latin word communis, which means 'common', so, when we communicate, we are essentially trying to establish a commonality with another person (Overton, 2007, p. 6). In our case, the commonality Overton mentions is business. Thus, business communication can be defined as exchanging business-related messages, usually in a business context. Of course, the four main elements needed in order for communication to take place are usually accompanied by additional ones like medium, encoding, decoding, feedback, context and noise. Noise refers to anything which tends to distort the message in the process of sending and receiving messages and, consequently, it can be listed under the common barriers to communication. Business English students usually point out that foreign language competence and cultural differences seem to be the most prevalent obstacles when it comes to effective business communication, though arguably the former is easier to overcome. English is a lingua franca and, if everything else fails, one can always use the services of an interpreter or even a translation app when there 
is an emergency. Intercultural competence, on the other hand, is more difficult to achieve, although they both take practice.

A look at the research literature on business communication reveals multiple factors contributing to the way a message is transmitted and perceived at the other end, the different codes within language, like verbal, prosodic, paralinguistic, kinesic and standing features (Ellis and Beattie, 1986, p. 17), concepts like register, dialect and accent (Hartley and Chatterton, 2015, pp. 57-58), while also differentiating between verbal barriers to communication, like inadequate knowledge or vocabulary, differences in interpretation, inappropriate use of expressions or ambiguity and polarization and nonverbal ones like inappropriate conflicting signals or distractions (Newman and Ober, 2013, pp.10-12). Moreover, based on the form of communication (spoken, written, non-verbal), we can encounter different combinations of the above-mentioned factors, which contribute to the uniqueness of each situation. Some basic functions of business communication, as identified by Bennie (2009) are: to pass on information, to persuade people to buy a product or use a service, to discuss an issue, to recommend a course of action, to make or answer a request or a complaint (Bennie, 2009, p.1), but choosing whether to initiate it orally or in writing "will depend on the circumstances, and to some extent on the person or people you are addressing” (Bennie, 2009, p. 2). For example, in some contexts, the speaker will choose oral communication for speed or to receive instant feedback from the audience (both verbal and non-verbal), while in other cases written communication is preferred to retain a permanent record, to send the same message to a number of people or to be able to think carefully about what you want to say (Bennie, 2009, p. 2). Choosing oral over written communication or vice versa might also depend on the profession. Chan (2020, pp. 2-3) mentions several studies which showed that the use of spoken communication is particularly important in the case of engineers, bankers and nurses, although writing and reding emails, memos and reports were also a significant part of people's jobs.

Business communication happens mostly within a company and there are a lot of books addressed to students (Beebe and Mottet, 2013; Guffey and Loewy, 2016; Newman and Ober, 2013), managers and corporate workers (Bennie, 2009; Clutterbuck and Hirst, 2002; Hartley and Chatterton, 2015; Simon, 2015) detailing the specific situations and types of written or oral communication that can be used in order to improve the overall flow of information. Also, one may find information about successful communication in relation to leadership and organisational structure (Beebe and Mottet, 2013; Hartley and Chatterton, 2015; Newman and Ober, 2013), together with dealing with intercultural differences (Tuleja, 2017) and using ICT (Clutterbuck and Hirst, 2002; Newman and Ober, 2013). However, business communication is not limited to the constraints of one company, not even to the same city or country. In an increasingly globalised world, business people are travelling abroad to meet business partners and negotiate deals, acting as representatives of their respective companies and cultures. The question asked in this paper is whether both internal and external types of business communication are confronted with the same barriers, what they are nowadays and what can be done to help business students prepare for such challenges.

As previously stated, during our preliminary discussions about business communication, students often identify foreign language competence and cultural differences as the most difficult obstacles to being able to communicate effectively. Granted, these two may not be a problem in the case of internal communication, unless that 
particular company has a significant number of employees from different cultural backgrounds. Most likely, they become an issue in the case of external communication, when the situation requires travelling abroad and/or frequent meetings with foreign partners or customers. Typically, companies would provide their key employees with the opportunity to take foreign language and cultural competence courses alongside providing training sessions on leadership, public relations or negotiating, all with the end goal of having well-prepared staff that can work together and also be able to interact efficiently with anyone outside the company.

Other traditional barriers to communication, in general, and business communication, in particular, may be:

a) lack of interpersonal skills,

b) language issues (even in the case of a person's mother tongue),

c) limited specialised vocabulary,

d) lack of expertise in the business field,

e) lack of practice,

f) lack of listening skills,

g) poor knowledge of non-verbal cues,

h) lack of business writing / presentation / negotiating / team-working / time management (Beebe and Mottet, 2013) skills,

i) limited knowledge of business etiquette and ethics (Guffey and Loewy, 2014).

In the case of (Business) English seminars, raising students' awareness of such issues usually comes as a package with the linguistic input. But we must also acknowledge the added barriers that we have been confronted with for the past year and a half, as the world experienced the switch to mostly online communication.

\section{Business communication during a global pandemic}

When the pandemic hit, in early 2020, almost everything we thought we knew about business communication was suddenly challenged. Depending on national lockdown regulations, employees spent anywhere between a few weeks to months on end not being able to interact face-to-face and using different methods of working remotely, which was probably the most we have ever relied on ICT in our history. From working to shopping and even to connecting with friends and family, we were forced to adapt to this sudden loss of unmediated interaction and make changes by learning along the way. At this point in time, with the world still going through the disruption brought about by the pandemic, it is difficult to state the impact it has had on business communication. However, as they say, the show must go on, since businesses need to find ways to stay afloat while employees are doing their best to do their jobs in less-than-ideal circumstances. And it seems that we are craving the kind of efficiency we expect from business communication in our everyday lives as well, since our leaders have not been very coherent in providing guidelines for the past year or so (Jacobs, 2020).

The implications for everyone involved in any type of virtual information exchange were that we first had to adapt to the new channel and then find a way to get the message across given the new obstacles to effective communication. For Business English teachers and students, this basically meant that they had to overcome the barriers of online communication in general in order to be able to discuss about the barriers to business 
communication in particular! This switch to online communication will undoubtedly have effects on what will be taught in the future. Already, there are companies where it has been decided to permanently implement the hybrid working model (both on-site and online), which indicates that both employees and employers have realised that business communication has remained effective even with people working remotely. We do not necessarily need to be in the same room to work together (of course, this is not the case for all fields of activity), so we might witness a worldwide revolution in working practices and this should be reflected in what we teach our students.

\section{Learning how to overcome barriers to business communication through business english courses}

So, how do we help our students understand what business communication is about, what barriers they might encounter in a work setting, how to overcome them and how to adapt to the challenges brought about by the current global situation?

The students at the Faculty of Economics and Business Administration in Iași are enrolled in ten distinct learning programmes at undergraduate level (Accounting and Business Information Systems, International Economics and Business, Trade, Tourism and Services, Banking and Finance, Business Information Systems, Management, Marketing, Economic Statistics and Forecasting, Public Administration and Business Administration - in English) and twenty-two master's programmes following roughly the same domains. Based on their specialisations, they could all benefit from training in business communication, especially when it is done in a foreign language. All undergraduate students study English for four semesters (or more for some specific programmes), which means they have the opportunity to improve their language level and also familiarise themselves with the implications of business communication in a foreign language.

In the following sections of this paper, I will provide examples of how we tackle the communication barriers identified above in the Business English classroom and how we contribute to familiarizing our students with the theory and practice of business communication. The overall objective of our Business English course is to help develop both their hard skills (related to language and specialized business knowledge) and soft skills (interpersonal communication and other general life/work skills like preparing and delivering presentations, business writing, negotiating, team-working, time management etc.) through a variety of activities.

\section{Hard Skills}

\section{a) Foreign Language Competence}

Foreign language issues are the main focus of our seminars with undergraduate students, especially those in their first year of study. In dealing with mixed-ability groups who have not been previously tested for language competence level, discussing more complex issues before making sure basic language knowledge is internalised is not viable. Thus, while topics related to the business world are tackled throughout the four-semester course, during the first year there is a lot of focus on grammar and vocabulary building. Gradually, more advanced notions are introduced and distinctions are made based on notions like register, levels of formality, specialised phrases etc. 
Achieving communicative competence (i.e., the learner's ability to use the language in order to communicate successfully) is at the core of most language teaching approaches nowadays, because the end result in business communication is maybe less about knowing all the technical terms or having the skills to deliver an outstanding presentation (although these might be the focus at some point or another), but more about being able to express exactly what you want to say, clearly, concisely and appropriately, in a language that is not your native one. With a lot of the business communication (both spoken and written) now happening through online platforms, it is more important than ever to choose your words carefully in a foreign language so that misunderstandings are avoided.

b) Specialised Vocabulary and Business Expertise

When making the transition from general English (taught in schools) to ESP (taught in universities, language schools or in-company), students are faced with accumulating as much specialised vocabulary as possible. Grammar and syntax rules stay the same, but in order to be able to encode and decode messages in a business environment, students need to understand what certain words mean (sometimes the meaning changes depending on the context) in order to perform the tasks required from them. However, since the vast majority of undergraduates is pre-experienced, there is no specific business field to focus on. Even though a student might specialise in marketing, for instance, it is not at all uncommon for him/her to find a job in management or finance, particularly since all first-year courses are the same for all students at our faculty. This means that the teacher will have to cover more general topics at this level, rather than insist on extremely specialised vocabulary items.

\section{Soft Skills}

\section{a) Interpersonal and Listening Skills}

When it comes to interpersonal skills, it is important to acknowledge that practice is the best way to prepare our students for real life human interaction, be it direct or indirect. This involves providing opportunities for them to work in pairs or groups, prepare team presentations, collaborate on projects, encouraging them to attend conferences and networking events. By essentially treating the classroom as a potential work environment, through completing language-related activities, students indirectly learn to collaborate with their colleagues, follow instructions, receive and provide feedback, brainstorm ideas, ask for help, negotiate etc., which are all skills that employers are looking for and are at the basis of effective business communication, since there are very few jobs which actually do not require one to interact with other people.

With remote learning and working due to the pandemic, interpersonal interaction has suffered greatly. Beyond the inherent technical issues which hinder the actual exchange of (written or oral) messages, it is significantly more difficult for people to establish rapport, read non-verbal cues, decode hidden meanings or be mindful of cultural sensitivities when communicating through videoconferencing platforms or on the phone. Multinational conglomerates where employees had been using internal chat software and distance-communication platforms for several years before the pandemic may have been more prepared for the switch to online interaction (though employees in the same department would no doubt attend regular face-to-face meetings and teambuilding activities), but in the fields where physical interaction used to be the norm, blockages are inevitable. What can be done, at the beginning of a new academic year with little chances 
of on-site activities, is to encourage students to make the most of what technology has to offer. It is important for them to understand, for example, that using their webcam during their seminars is much more than an inconvenience, it is an essential way to communicate effectively, since a large part of the message is transmitted visually. This also means that there is significantly more effort required on their part to encode the message, avoid noise, get it across and then receive and decode feedback.

b) General (Work) Skills

A lot of different types of skills can be included in this very general category and while most of them are not limited to the work environment, it is in that context that they become necessary to master. A brief look at the job advertisements posted on various recruitment websites reveals that many recruiters and managers today are looking for future employees who already master skills like time management, negotiating, team-working, preparing and delivering presentations, conflict management etc., alongside the required minimum level of foreign language competence (the more languages an applicant can speak, the better). Acquiring these skills has been the indirect objective of all teachers throughout the student's school instruction, but they continue to be part of the learning goals at university level, as they are essential to our students' future professional development. During our Business English courses, as we go through business-related topics like company organization and culture, advertising, management, cooperation and competition or human resources and recruitment, we also work on the skills needed to activate in these different business areas. Attending meetings, reading and sending reports, listening to and delivering presentations, sending or receiving emails are all part of our work lives nowadays, including in the case of what are considered non-desk jobs. Business writing in English is of particular concern for us, since the written word has significantly more weight to it and, in business, oral communication is normally followed by some sort of written agreement. Thus, our second-year undergraduate Business English students are specifically required to practise writing their $\mathrm{CV}$, application letter and several types of common business correspondence in preparation for their future careers. This is especially relevant these days, since the pandemic may have accentuated the need for written agreements and information exchange as a result of business communication being conducted almost exclusively without physical interaction.

\section{c) Intercultural Competence, Business Etiquette and Ethics}

A lot has been said about the importance of cultural awareness, intercultural competence and cross-cultural communication (Harris et al., 2004; Jackson, 2014) especially in relation to learning a foreign language, since they should come as a package. This is also the case of the Business English courses at our faculty, as we recognise the necessity of helping familiarise our students with the realities of the business world. Globalisation has opened doors for them to travel and study abroad, as well as apply for positions around the world, but it has also meant that international corporations have expanded their business to our country and are looking for potential employees who are already familiar with working in a multicultural environment. Students who are currently working for such companies have confirmed that they are required to use both their spoken and written English skills as they communicate with customers abroad or attend meetings, workshops and training programmes with fellow employees from other countries, as well 
as draw on their knowledge of business etiquette and ethics, which is are also touched upon during their Business English classes.

As previously mentioned, all students at our faculty study Business English for four semesters (except for those specialising in Business Administration, who study Legal English). Regardless of specialisation, however, the concept of intercultural competence is introduced early on, as it is a significant part of the syllabus. Moreover, students specialising in Economics and International Business continue their training in English in their third year with a Business Communication course. We also offer several master's programmes where intercultural communication is taught in English, including one named International Business and Intercultural Strategies. This goes to show that there is a real preoccupation for such issues at our faculty, since it is up to us to prepare our students for the communication obstacles lying ahead, in the vast world of business.

\section{Conclusions}

Business communication is quite a loose term, encompassing a very large amount of specialised information, skills, factors and conditions, all necessary in order for the process to take place successfully. In fact, business communication is the engine that drives people and businesses, it brings them together and is at the basis of economic activities worldwide. It is not something that can be taught in a few weeks, since it involves a lot of practice and benefits from significant professional experience. The subject is covered by Business English courses, but students certainly benefit from the input provided by their other professors as well, who specialise in the different areas connected to Economics and Business Administration.

The current health crisis has definitely changed some of the ways in which we used to communicate and the way business was conducted, but it has also hopefully opened some new doors and at the very least it has showed that communication will take place, no matter what. In terms of communication barriers, with the use of online platforms, they seem to have been reduced in number, rather than multiplied. Social media, podcasts, wikis or blogging are now used on a regular basis, as we witness the digitalisation of the business world at a staggering pace. It is up to us to keep up with all that technology has to offer, but it is also up to educational institutions and companies to teach us how to implement it at work. As we continue to adapt to the new technologies, we will continue to be impacted by new trends, so it is essential that we evolve at the same pace as our students and the requirements of the job market, because it in turn reflects the communication needs at the workplace. Business communication will likely continue to develop in the future, and whatever other barriers might appear, we will certainly find a way to overcome them, as information exchange is the essence of who we are as human beings and of society itself.

\section{References}

1. Beebe, S.A., Mottet, T.P., 2013, Business Professional Communication. Principles and Skills for Leadership. 2nd ed. Boston: Pearson.

2. $\quad$ Bennie, M., 2009. A Guide to Business Communication. How to Write and Speak English Well in Every Business Situation. 5th ed. Oxford: How To Books Ltd.

3. Chan, Mable. 2020. English for Business Communication. Abingdon: Routledge. 
4. Clutterbuck, D., Hirst, S., 2002. Talking Business: Making Communication Work. Burlington, MA: Butterworth-Heinemann.

5. Ellis, A. and Beattie, G., 1986. The Psychology of Language and Communication, London: Weidenfeld \& Nicolson.

6. Guffey, M. E., Loewy, D., 2016. Essentials of Business Communication. 10th ed. Electronic version. Boston: Cengage Learning.

7. $\quad$ Harris, P. R., Moran, R.T. and Moran, S.V., 2004. Managing cultural differences. Global leadership strategies for the 21st Century. 6th edition. Burlington, MA: Butterworth-Heinemann.

8. Hartley, P., Chatterton, P., 2015. Business Communication. Rethinking your professional practice for the post-digital age. 2nd ed. New York: Routledge.

9. Jackson, J., 2014. Introducing Language and Intercultural Communication. Abingdon: Routledge.

10. Jacobs, G., 2020. Business Communication and COVID-19. Business Communication Research and Practice, $\quad$ pp. $73-75 \quad$ Aonline]. Available at: https://www.researchgate.net/publication/349546057_Business_Communication_and_COVID-19 [Accessed 27 September 2021].

11. Newman, A., Ober, S., 2013. Business Communication. In Person, in Print, Online. Electronic version. Mason, $\mathrm{OH}$ : South-Western.

12. Overton, R., 2007. Business Communication. E-book version. Boat Harbour, NSW: Martin Books Pty Ltd.

13. Simon, P., 2015. Message Not Received. Why Business Communication is Broken and How to Fix It. Hoboken, NJ: John Wiley \& Sons Inc.

14. Tuleja, E. A., 2017. Intercultural Communication for Global Business. How leaders communicate for success. New York: Routledge. 